\title{
Cost of diseases in international perspective
}

\author{
MARC A. KOOPMANSCHAP, LEONA VAN ROIJEN, LUC BONNEUX, GOUKE J. BONSEL, FRANS F.H. RUTTEN, \\ PAUL J. VAN DER MAAS, THE TECHNOLOGY ASSESSMENT METHODS PROJECT TEAM *
}

\begin{abstract}
This study compares the health care costs of The Netherlands with the United States and Sweden and estimates the impact of demographic change on costs. Total health care costs were allocated to disease, age, sex and specific subsectors. For The Netherlands $75 \%$ of the costs in 1988 were assigned to specific diseases. Costs of mental disorders and other chronic non-fatal diseases dominate, followed by cardiovascular diseases. The effect of age is strong from age 70 years onwards. The effect of sex, adjusting for age, is small, except for elderly women, who are more expensive. Both total and disease-specific costs are similar in The Netherlands and Sweden, but differ from those in the US. The available data suggest that the differences in medical practice and health care systems may explain a substantial part of the divergent results; demographic or epidemiologic aspects seem less important. Ageing induces, in the Dutch case, a modest $0.7 \%$ annual increase in costs. The contribution of other forces in the increase of costs is probably more important. A structural upward pressure on costs also prevails in The Netherlands and Sweden, but it is more prominent in the US, due to a large amount of expensive surgery and high administration costs.
\end{abstract}

Key words: costs of illness, economic evaluation, international comparison, health policy, ageing

$\mathrm{T}$ epidemiology, medical practice, economic factors including the type of health insurance system and cultural circumstances. Having stated this, it is surprising that the recent debate on value for money in various health care systems focuses largely on aggregate expenditure levels, paying little attention to the important relation between disease and medical consumption. ${ }^{1}$ In this paper the costs of illness are estimated for The Netherlands, covering the entire range of diseases and providing data on disease-specific costs, according to age, sex and health care sector. Next the level of medical care costs and the distribution according to disease will be compared with the United States and Sweden. For some diseases we will indicate whether the remarkable differences in costs appear to be due to divergence in demography and epidemiology or whether supply and financing of health care are most relevant in explaining these differences. We cannot provide a complete analysis for all diseases, as this requires a reliable international overview of (longitudinal) morbidity data, which is currently lacking. Still this paper may contribute to the debate on the quality and costs of health care.

Another important policy item is estimating the consequences of ageing. It will be shown how rapidly medical

* M.A. Koopmanschap, GJ. Bonsel, Department of Public Health and Institute for Medical Technology Assessment, Erasmus University, Rotterdam, The Netherlands

L. van Roijen, L. Bonneux, P.J. van der Maas, Department of Public Health, Erasmus University, Rotterdam, The Netherlands

F.F.H. Rutten, Institute for Medical Technology Assessment, Erasmus University, Rotterdam, The Netherlands

Apart from the authors, the team comprises: JJ.M. Barendregt

L.J. Gunning-Schepers, J.D.F. Habbema, B.A. van Hout, B.M. van Ineveld,

C.W.N. Looman, G.J. van Oortmarssen

Correspondence: Marc A. Koopmanschap, Institute for Medical Technology

Assessment, Erasmus University, P.O. Box 1738, 3000 DR Rotterdam, costs may increase due to demography alone, compared with the impact of other expenditure increasing factors.

\section{METHODS}

Cost of illness in The Netherlands

Total health care costs in The Netherlands, excluding care in old peoples homes and social work, amounted to 39.8 billion Dutch guilders (ECU 15.9 billion), according to the national Financial Overview of -Health Care. ${ }^{2}$ These costs were allocated to age, sex, health care sector and disease categories. ${ }^{3}$ To this end health care was divided into 18 sectors. All diseases of the International Classification of Diseases $9-\mathrm{CM}^{4}$ were assigned to 48 disease categories, using as criteria comprehensive data on morbidity, mortality, costs and expected developments. They can be aggregated to the standard 17 ICD-chapters. The primary diagnosis of patients was used to assign costs to specific diseases.

Most data were extracted from national registers with nearly complete coverage. The Durch hospital registration system was described by Casparie. ${ }^{5}$ For some other sectors we use data from large surveys such as the Dutch National Health Interview Survey, ${ }^{6}$ which is comparable to its US counterpart NHIS. For a few sectors insurance data were used (table 1). The available data on diagnosis were all registered by the responsible physician or nurse, conforming to the ICD 9-CM rules. Costs incurred by dental or matemity services were allocated to dental diseases and pregnancy and delivery respectively. Information on diagnosis was not complete or absent regarding care for physically handicapped, home help, pharmaceuticals, general preventive care, patient transport and administration. They represent $25 \%$ of the health care costs. For each health care sector total costs were assigned to age, sex and diagnosis by using utilization of services, the 
number of patients or the expenditures per group of patients (table 1). For example, the number of visits to physical therapists determines the distribution of costs for physical therapy; assuming each visit has the same cost. Regarding hospitals and nursing homes, we used the number of hospital days; for psychiatric care and care for mentally or physically handicapped the number of patients was used to allocate costs. For most ambulatory services we used the number of visits to attribute costs. In the case of maternity services, appliances and patient transport cost allocation were based on expenditures.

Data on age and sex were available for all health services, except for general preventive care and administration; considered as indivisible goods, they have been assigned by assuming equal costs per citizen.

\section{International comparison}

The results for The Netherlands will be compared with Sweden ${ }^{7}$ and the US. ${ }^{8}$ All 3 studies use the primary diagnosis to assign costs to disease categoties. The data used are a mixture of national and regional registrations and samples and surveys on health care utilization and costs. In the US study non-personal health costs such as costs for government public health care and insurers and government administration were excluded. Costs of patient transport were not allocated to a specific disease (table 1). In Sweden, home help is a part of the social services and was therefore excluded. The costs of dental care, appliances, patient transport, government public health care and administration were not assigned to disease.

The proportion of costs which could be assigned to specific diseases is similar in the three countries. In Sweden $78 \%$ was assigned, in The Netherlands $75 \%$ and in the US $82 \%$ (table 2). As detailed cost analyses of the entire health care system would have been too complicated, each study used aggregated data on utilization and costs to assign costs to diagnosis, age and sex. The procedures used in distributing costs to diagnosis are fairly similar, with a few exceptions. The US study uses estimates of

Table 1 Overview of methods and data used for allocation of costs to disease categories per health care sector in The Netherlands (NL), Sweden and the US

\begin{tabular}{|c|c|c|c|c|c|c|}
\hline Health care service & $\begin{array}{l}\text { \% Health care } \\
\text { costs NL }\end{array}$ & $\begin{array}{l}\text { Data on } \\
\text { diagnosis NL }\end{array}$ & $\begin{array}{l}\text { Data type and } \\
\text { source NL }\end{array}$ & Allocation NL & Allocation Sweden & Allocation US \\
\hline \multicolumn{7}{|l|}{ Hospital } \\
\hline $\begin{array}{l}\text { Nursing and } \\
\text { physician services }\end{array}$ & 32 & + & National register & Hospital days & \multirow{2}{*}{$\begin{array}{l}\text { Hospital days and } \\
\text { cost per day } \\
\text { Out-patient visits }\end{array}$} & \multirow{2}{*}{$\begin{array}{l}\text { Hospital days and } \\
\text { expenses per day } \\
\text { Out-patient visits } \\
\text { Surgical procedures }\end{array}$} \\
\hline Surgery & 3 & + & National register & $\begin{array}{l}\text { Surgical procedures } \\
\text { and tariffs }\end{array}$ & & \\
\hline Nursing homes & 10 & + & National register & Nursing home days & Nursing home days & $\begin{array}{l}\text { Residents and } \\
\text { monthly expenses }\end{array}$ \\
\hline \multicolumn{7}{|l|}{ Psychiatric care } \\
\hline In-patient & 6 & + & National register & Residents & Expenditures & Residents \\
\hline Out-patient & 2 & + & National register & Clients & Expenditures & Psychiatric visits \\
\hline $\begin{array}{l}\text { Care for mentally } \\
\text { retarded }\end{array}$ & 6 & + & National register & Residents & Expenditures & Residents $^{b}$ \\
\hline $\begin{array}{l}\text { Care for physically } \\
\text { handicapped }\end{array}$ & 3 & +- & $\begin{array}{l}\text { Registers and } \\
\text { samples }\end{array}$ & Residents & Not allocated & Residents ${ }^{b}$ \\
\hline General practitioner & 5 & + & $\begin{array}{l}\text { Detailed sample } \\
\text { GP and patients }\end{array}$ & Visits & Visits & Visits \\
\hline District nursing & 2 & + & Regional register & Visits & Visits & Hospital days ${ }^{a}$ \\
\hline Home help & 4 & - & Sample & Visits & Not allocated ${ }^{c}$ & Hospital days $^{\text {a }}$ \\
\hline Matemity services & 1 & + & Insurers data & Expenditures & Expenditures & Visits \\
\hline Physical therapy & 3 & + & Sample & Visits & Visits & Hospital days ${ }^{a}$ \\
\hline Dental care & 4 & + & Dutch HIS & Visits & Not allocated & Visits \\
\hline Drugs & 9 & - & Dutch HIS & Prescriptions & $\begin{array}{l}\text { Prescriptions and } \\
\text { prices }\end{array}$ & Physician visits \\
\hline Eyeglasses and appliances & 2 & + & Insurers data & Expenditures & Not allocated & $\begin{array}{l}\text { Persons glasses/ } \\
\text { hearing aids }\end{array}$ \\
\hline $\begin{array}{l}\text { Governmental public } \\
\text { health care }\end{array}$ & 2 & +- & $\begin{array}{l}\text { Government } \\
\text { department }\end{array}$ & $\begin{array}{l}\text { Equal costs per } \\
\text { person }\end{array}$ & Not allocated & Not allocated \\
\hline Patient transport & 1 & - & Insurers data & Expenditures & Not allocated & Not allocated \\
\hline $\begin{array}{l}\text { Administration (insurers } \\
\text { and government) }\end{array}$ & 6 & - & $\begin{array}{l}\text { Government and } \\
\text { insurers }\end{array}$ & $\begin{array}{l}\text { Equal costs per } \\
\text { person }\end{array}$ & Not allocated & Not allocated \\
\hline
\end{tabular}

+: Information on diagnosis conforming to $\mathrm{ICD} 9 \mathrm{CM}_{;}+-$: Information on diagnosis partially conforming to ICD 9-CM

$\rightarrow$ No information on diagnosis available

a: Costs were allocated to disease, using the distribution of hospital days

b: Not allocated separately, as they are included in the hospital sector

c: In Sweden home help is not included in health care but in social services 
costs per hospital day by diagnosis category (table 1). In the Swedish study, costs per hospital day were made disease-specific, by using cost estimates for several hospital departments. For The Netherlands, we assumed equal cost per day for all diseases, as reliable disease-specific data on the costs per hospital day are currently not available. The Dutch data on non-hospital care appear to be more complete and reliable. For example, in the US study the costs of several home health care services had to be assigned to diseases, using the distribution of hospital days.

\section{Demography and costs}

Using the estimated mean costs per person by disease, age and sex for 1988, we calculated future health care costs, on the basis of expected demographic development. ${ }^{9} \mathrm{We}$ used 2030 as the end-point of our predictions, when ageing of the Dutch population is expected to reach its maximum. In order to relate the increase in costs to expected economic growth we used the 'Europe-scenario' drawn up by The Netherlands Central Planning Bureau, ${ }^{10}$ predicting a $2.8 \%$ yearly increase in real GNP.

Table 2 Distribution of direct costs by disease categories (17 chapters of the ICD 9-CM) in the US 1980, Sweden 1983 and The Netherlands 1988 in percentages of total direct costs

\begin{tabular}{|c|c|c|c|}
\hline $\begin{array}{l}\text { Disease category } \\
\text { (ICD chapters) }\end{array}$ & $\begin{array}{c}\text { US }^{\mathrm{a}} \\
\%\end{array}$ & $\begin{array}{c}\text { Sweden } \\
\%\end{array}$ & $\begin{array}{c}\text { The Netherlands } \\
\% \\
\end{array}$ \\
\hline Infective diseases & 1.8 & $1: 6$ & 1.0 \\
\hline Neoplasms & 5.5 & 5.1 & 4.6 \\
\hline $\begin{array}{l}\text { Endocrine and metabolic } \\
\text { disorders }\end{array}$ & 3.1 & 2.3 & 1.7 \\
\hline Diseases of the blood & 0.4 & 0.5 & 0.3 \\
\hline Mental disorders & 8.3 & 21.1 & 19.9 \\
\hline $\begin{array}{l}\text { Disease of the nervous } \\
\text { system }\end{array}$ & 7.1 & 4.2 & 3.8 \\
\hline Cardiovascular diseases & 13.6 & 12.3 & 8.7 \\
\hline Respiratory diseases & 7.0 & 5.0 & 3.1 \\
\hline $\begin{array}{l}\text { Disease of the digestive } \\
\text { system }\end{array}$ & 12.9 & 3.8 & 7.6 \\
\hline Genitourinary diseases & 5.1 & 3.0 & 2.7 \\
\hline Pregnancy and delivery & b & 2.7 & 3.5 \\
\hline Diseases of the skin & 2.5 & 1.7 & 0.9 \\
\hline Locomotor diseases & 5.5 & 3.9 & 7.0 \\
\hline Congenital anomalies & 0.5 & 0.5 & 0.4 \\
\hline Perinatal diseases & b & 0.5 & 0.9 \\
\hline Symptoms & 1.6 & 5.1 & 4.3 \\
\hline $\begin{array}{l}\text { Accidents, poisoning and } \\
\text { violence }\end{array}$ & 7.7 & 4.8 & 4.3 \\
\hline Other diseases & $3.6^{\mathrm{b}}$ & 0.0 & 0.0 \\
\hline Not allocated & $14.2^{\mathrm{a}}$ & 21.9 & 25.2 \\
\hline Total & 100 & 100 & 100 \\
\hline
\end{tabular}

a For comparability, the US percentages derived by Rice ${ }^{8}$ were corrected for non-personal health care costs (e.g. insurers and government administration and government public health services). These costs now make up the lion's share of unallocated costs

b For the US the costs of pregnancy and perinatal diseases could not be

\section{RESULTS}

Costs by disease and sex

In figure 1 we show the costs by 17 disease categories and sex. Mental disorders (including mental retardation) generate by far the highest costs, accounting for $20 \%$ of total costs, followed by cardiovascular diseases $(9 \%)$, disease of the digestive system ( $8 \%$, including dental diseases) and locomotor diseases $(7 \%)$. The most expensive disease categories are chronic, non-fatal illnesses. Cardiovascular diseases and cancer, accounting for $71 \%$ of Dutch mortality, make up only $14 \%$ of the health care costs. Women account for $57 \%$ of total costs, including the costs of pregnancy. The distribution of costs among ICD-chapters is quite similar for both sexes. Costs of cardiovascular disease are relatively more important for men (10 versus $8 \%$ ), while for women locomotor diseases are relatively more important ( 8 versus 6\%). Due to the standard registration procedure, the small amount of pregnancy-related costs for men are attributable to healthy babies who stay a short period in hospital, after birth. The results for the US $^{8}$ are similar. Rice ${ }^{8}$ concludes that women account for $59 \%$ of health care costs and that the distribution of costs by disease is not very sex specific.

\section{Costs by disease and age}

The pattern of costs of illness related to age is quite diverse. For the age group 0-19 years, costs of mental disorders, gastrointestinal diseases (in particular dental care) and perinatal diseases are the most expensive. In the age group 20-44 years, costs of mental disorders still dominate, followed by costs of pregnancy, dental diseases and locomotor diseases. From age 45 to 64 years cardiovascular disease, locomotor disease and cancer represent the greatest costs, followed by mental disorders. Costs of cardiovascular disease are the most important in people aged 65-79 years. From age 80 years onwards, the typical impairments of the most elderly are reflected in high costs for dementia, stroke, locomotor disease and non-traffic accidents.

\section{Costs by age and sex}

Figure 2 presents the mean annual costs per person by age and sex. These costs rise gradually from dfl 1,000 for age $5-9$ years to 3,000 for age $55-59$ years. From age 60 years on, costs accelerate, reaching a maximum of dfl 18,000 for age 85 years and older. Given their age, differences in costs between men and women are small, except for the higher costs for women of age 80 years and older. The causes of this exception are at least 2-fold: these women are on average older than men in the same age group and more often single, which increases their probability of hospitalization. ${ }^{11}$ The higher costs for women aged $20-44$ years are due to pregnancy and childbirth. Our Dutch cost estimates correspond quite closely to results for the US. In 1980 the mean costs per US citizen older than 65 years were 2.75 times the mean for all citizens ${ }^{12}$; the corresponding Dutch ratio was 2.86 in 1988 . Waldo's ${ }^{13}$ estimates for health care costs by age for the US in 1987 confirm this conclusion. 


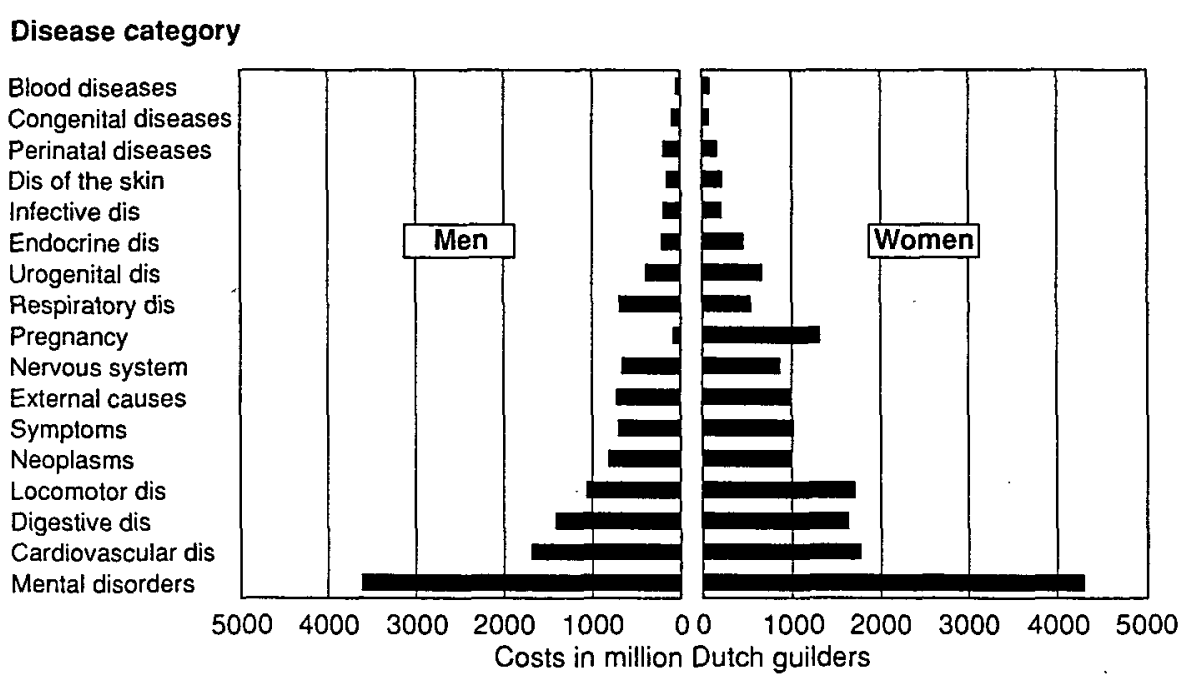

Figure 1 Costs of health care by disease category and sex for The Netherlands 1988, in million Dutch guilders

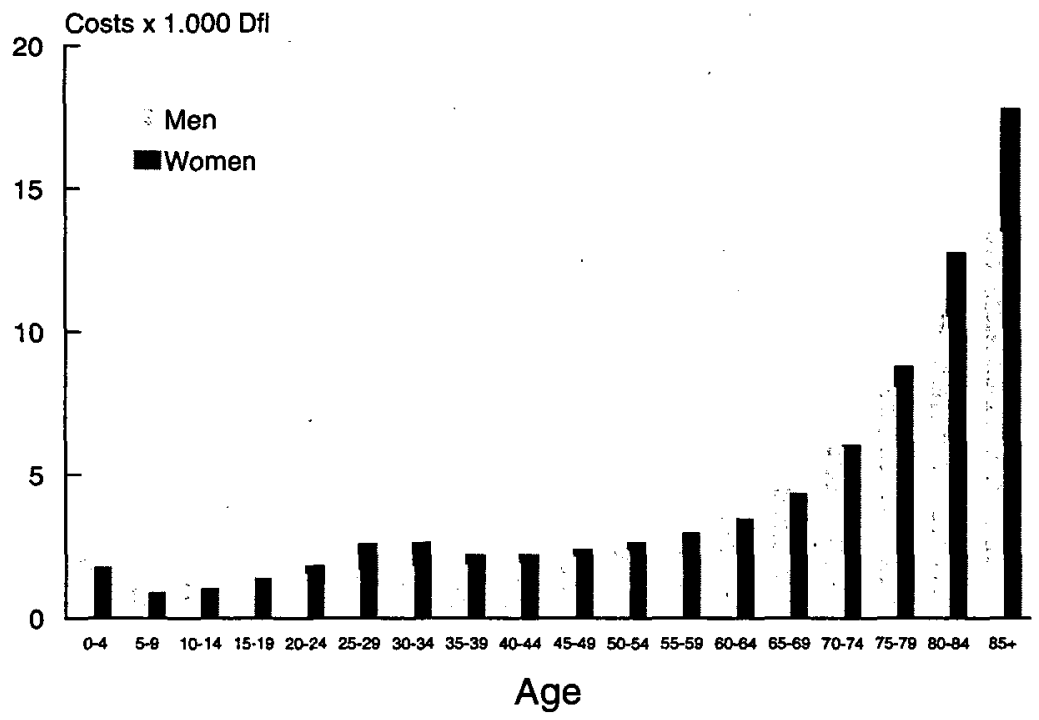

Figure 2 Mean health care costs per year per person by age and sex for The Netherlands 1988 , in thousand Dutch guilders

International comparison

Table 2 presents the distribution of health care costs by ICD-chapters for the US (1980), Sweden (1983) and The Netherlands (1988). A satisfactory explanation of all differences requires a systematic analysis of health care systems, demography and epidemiology, which is beyond the scope of this study. The main obstacle for a complete analysis is the lack of reliable, comparable data regarding disease-specific morbidity. Nevertheless, our partial comparison reveals interesting outcomes.

The results for Sweden and The Netherlands are very similar; the low costs for diseases of the digestive tract in Sweden are due to the omission of dental care in Lindgren's ${ }^{7}$ study. The US pattern of costs deviates on several points from the two European countries. The low costs for mental disorders in the US probably do not reflect a lower prevalence. Two meta-analyses show no difference in prevalence rates of dementia for Europe $^{14}$ and the US. ${ }^{15}$ For mental retardation evidence is less firm, but prevalence estimates for children in the US and Scandinavia are in the same range. ${ }^{16,17}$ Therefore, it appears that the low costs for mental illness in the US are due to the small extent of in-patient psychiatric care: the number of beds per 1,000 citizens in psychiatric hospitals in The Netherlands and Sweden is much higher than in the US, both for 1980 and 1989 (table 3).

For cardiovascular disease comparative morbidity data are not available, but the high US costs may be at least in part related to more surgery, as the relative frequency of coronary artery bypass grafting (CABG) in the US in 1988 was more than twice the Dutch and Swedish rate (table 3 ). In addition, the rate of increase in performing bypasses between 1985 and 1988 for the US was much larger than for The Netherlands. The automatic reimbursement of costs in the US clearly provides an economic incentive for increasing the number of CABGs, whereas in The Netherlands and Sweden the number of bypasses is highly regulated. ${ }^{18}$ Regarding digestive diseases the story is analogous: the surgery rate in the US is 16.6 per 1,000 citizens as compared to 9.2 for The Netherlands, 19,20 whereas in both countries surgery for digestive diseases makes up $16 \%$ of total surgery.

The substantial costs of accidents, poisoning and violence in the US are undoubtedly due to their high incidence. The US mortality rate for traffic accidents involving passenger cars is twice as high as for The Netherlands and Sweden. As this cannot be explained by differences in lethality, it points to higher incidence, caused by the larger mobility in the United States. ${ }^{21-23}$ With respect to homicide an average US citizen has a 10 times higher risk of being killed than the average Dutchman, indicating a much larger incidence of accidents related to violence. ${ }^{23}$ Turning to total costs, table 3 shows that both the share 
of costs in GNP and the mean costs per capita are substantially higher in the US. Furthermore, the costs are still rising in the US while they are stabilizing in The Netherlands and Sweden. ${ }^{19}$ Hence, one may ask: what makes US health care so expensive?

If a less favourable age composition of the US population were the cause, standardizing the population of The Netherlands to that of the US regarding age and sex, ${ }^{24}$ combined with actual pro capita costs for The Netherlands, it should result in higher projected costs compared to the actual Dutch costs. However, this calculation gives almost identical costs, so differences in demography can be ruled out as an explanation. Moreover, although the Swedish population is considerably older, Swedish health care costs are still quite moderate.

Undoubtedly, the high administration costs in the US, especially within hospitals, play an important role in the expansion of costs. For the US, they were estimated to be between 19 and $24 \%$ of the total health care costs in 1987. ${ }^{25}$ Using the same definition with respect to administration costs for The Netherlands we estimate them to be $11-14 \%$ in 1988 (table 4).

Table 3 Public health and health care in The Netherlands, Sweden and the United States

\begin{tabular}{|c|c|c|c|c|}
\hline Item & $\begin{array}{l}\text { Year/ } \\
\text { gender }\end{array}$ & $\begin{array}{l}\text { The } \\
\text { Netherlands }\end{array}$ & Sweden & US \\
\hline Epidemiology & & 1988 & 1987 & 1988 \\
\hline \multirow[t]{3}{*}{ Life-expectancy at birth in years ${ }^{b}$} & Male & 73.7 & 74.2 & 71.6 \\
\hline & Female & 80.5 & 80.4 & 78.6 \\
\hline & & 1988 & 1987 & 1988 \\
\hline \multirow[t]{2}{*}{ Infant mortality rate per 100,000 live births ${ }^{b}$} & Male & 798 & 668 & 1099 \\
\hline & Female & 563 & 553 & 866 \\
\hline \multirow[t]{2}{*}{$\begin{array}{l}\text { Mortality rate for traffic accidents with } \\
\text { passenger cars per } 100,000 \text { persons }\end{array}$} & 1987 & 5.23 & 5.70 & 10.63 \\
\hline & & 1988 & 1987 & 1988 \\
\hline \multirow{2}{*}{$\begin{array}{l}\text { Mortality rate for homicide per } 100,000 \\
\text { persons } b\end{array}$} & Male & 1.1 & 1.5 & 12.8 \\
\hline & Female & 0.7 & 0.9 & 4.0 \\
\hline \multicolumn{5}{|l|}{ Costs } \\
\hline \multirow[t]{2}{*}{ Health care costs as share in GNP in \% } & 1988 & 8.2 & 8.5 & 11.4 \\
\hline & 1990 & 8.1 & 8.7 & 12.4 \\
\hline Costs per person US\$ PPP & 1990 & $1,182^{\circ}$ & 1,421 & 2,566 \\
\hline \multicolumn{5}{|l|}{ Input } \\
\hline $\begin{array}{l}\text { Number of pract physicians per } 1,000 \\
\text { inhabitants }\end{array}$ & 1988 & 2.4 & 2.9 & 2.3 \\
\hline \multirow[t]{2}{*}{ Psychiatric care beds per 1,000 inhabitants } & 1980 & 1.7 & 3.2 & 0.9 \\
\hline & 1989 & 1.6 & 1.8 & 0.6 \\
\hline Acute care hospital beds per 1,000 inhabitants & 1988 & 4.5 & 4.1 & 3.7 \\
\hline \multicolumn{5}{|l|}{ Output } \\
\hline Mean length of acute hospital stay & 1988 & 11.3 & 7.5 & 6.5 \\
\hline In hospital surgery per 1,000 inhabitants & 1988 & $56.8^{\mathrm{c}}$ & NA & 105 \\
\hline \multirow[t]{2}{*}{ CABG surgery per million inhabitants $d$} & 1985 & 480 & 250 & 780 \\
\hline & 1988 & 583 & $464^{e}$ & 1265 \\
\hline \multicolumn{5}{|l|}{ Incomes } \\
\hline Mean earnings per physician US\$ PPP & 1988 & $70,000^{f}$ & 48,000 & 144,700 \\
\hline $\begin{array}{l}\text { PPP: purchasing power parities; CABG: coronary artery by } \\
\text { Sources: if not indicated by superscript see reference } 19 \\
\text { a See reference } 21 \text {; b see reference } 23 \text {; c see reference } 20 \text {; } d \\
\text { e see reference } 32 \text {; personal communication }\end{array}$ & $\begin{array}{l}\text { pass graf } \\
\text { see refer }\end{array}$ & & & \\
\hline
\end{tabular}

Regarding input, the number of physicians and beds in acute care hospitals per citizen in the US is slightly smaller than for The Netherlands and Sweden (table 3), which cannot explain higher costs. Turning to output, the length of stay in acute care hospitals in the US is lower than in The Netherlands and comparable to Sweden, which would rather point to lower costs. A really striking difference is the 'high intensity' of US medicine, illustrated by the rate of in-patient surgical procedures which is approximately twice as high for the US as for The Netherlands (table 3). Studies of pacemaker implantation, ${ }^{26}$ endoscopy ${ }^{27}$ and carotid endarectomy ${ }^{28}$ indicate that overtreatment of insured patients is not exceptional in the US. The costs of 'defensive medicine' in the US were estimated to be US $\$ 15$ billion in 1989.29 This style of practising medicine may also be related to the competition between US hospitals concentrating on 'quality' rather than on price, resulting in the duplication of expensive equipment and services. Robinson and Luft ${ }^{30}$ have shown convincingly that in the US the amount of medical equipment within each hospital increases with the number of other hospitals in the neighbourhood. In The Netherlands, regional dispersion of expensive services is regulated by licensing, which reduces the inefficient use of medical equipment. Comparing prices of health care services between countries is not without problems, but an OECD ${ }^{31}$ study indicates that for the equivalent of US \$ 1 significantly more medical services can be bought in other OECD countries than in the US. Viewing the mentioned data on volumes and prices, it is not surprising that mean earnings of physicians in the US are three times as high as in Sweden and twice the Dutch level ${ }^{19}$ (S. Jendteg, personal communication) (table 3). The formidable liability insurance premiums for US physicians, which have grown by approximately $15 \%$ per year in recent years, ${ }^{29}$ contribute to the rise in health care costs, although the physician's net disposable income is not affected.

Demography and costs

For the years 2010 and 2030, we calculated the consequences for health care 
costs of expected demographic developments in The Netherlands, using the estimated mean costs per person by age and sex for 1988 . As presented in table 5 , total costs will rise by $1 \%$ per year during 1988-2030. Seventy per cent of this increase $(0.7 \%)$, is due to ageing, the remaining $0.3 \%$ being a result of population growth. During 2010-2030 ageing will be responsible for $90 \%$ of the increase in costs: $0.9 \%$ per year. For the period 1980 2040, Rice ${ }^{32}$ estimated US health care costs would grow by $1.1 \%$ per year, of which only $0.3 \%$ will be caused by ageing. Diseases for which costs are expected to rise faster than average are shown in table 5 . The forecasts for these diseases are quite reliable, as they depend largely on the life expectancy of the living population and for most of these diseases the pattern of care and costs is not expected to change radically. Costs of dementia, lung and prostate cancer, stroke and heart failure will rise substantially up to 2010 , but will increase more rapidly still in the decades thereafter, as the Dutch post-War baby boom reaches the age of 70 at which age medical consumption will accelerate (figure 2).

The $0.7 \%$ annual growth of costs due to ageing is quite modest when compared with expected long term economic growth: $2.8 \%$. Other forces than ageing seem to be more important in increasing health care costs. For example, in the majority of OECD countries, including the US, health care prices structurally tend to rise faster than in the rest of the economy. ${ }^{19,33,34}$ In part this is due to lower productivity growth in health care than in manufacturing industries, but it also may reflect the improved quality of medical services. This relative price increase of health care services acts as a continuous upward pressure on health care costs. During 1980-1990 health care prices in the US rose $2.75 \%$ more than general inflation and in Sweden $1.0 \%$, whereas in The Netherlands no difference occurred. 19

\section{DISCUSSION}

The international comparability of disease-specific data has been questioned recently. Stehbens ${ }^{35}$ demonstrated

Table 4 Administration costs (using Woolandler and Himmelstein's ${ }^{25}$ definition) as \% of total health care costs for the US 1987 and The Netherlands 1988

\begin{tabular}{|c|c|c|}
\hline Expenditure category & $\begin{array}{c}\text { The Netherlands } \\
1988 \\
\%\end{array}$ & $\begin{array}{l}\text { US } \\
1987 \\
\%\end{array}$ \\
\hline $\begin{array}{l}\text { Programme administration } \\
\text { and insurance overhead }\end{array}$ & 4.4 & 5.1 \\
\hline Hospital administration ${ }^{b}$ & $3.0-5.0$ & 7.8 \\
\hline Nursing home administration ${ }^{b}$ & 0.8 & 1.3 \\
\hline Physicians' overhead ${ }^{c}$ & 3.5 & $5.1-9.8$ \\
\hline Total & $11.7-13.7$ & $19.3-24.1$ \\
\hline
\end{tabular}

Sources:

a For the United States (all items), see reference 25;

for The Netherlands the calculation was based on reference 2

b For The Netherlands see reference 42

c For The Netherlands: personal communication that diagnostic errors in certified causes of death may result in unreliable mortality statistics, invoking wrong conclusions on epidemiologic trends. It is not known whether the misclassification bias as reported for causes of death is equally important for diagnosis related to medical consumption. However, the international comparison presented is limited to very broad disease categories: the 17 ICD-chapters. Although differences in casemix between countries within ICD-chapters may be substantial, misclassification between ICD-chapters appears to be less likely.

We used only the primary diagnosis of patients to assign costs to disease. This facilitates the comparison of results between diseases, a frequent problem in cost of illness studies, but it may underestimate costs of diseases which often prevail as co-morbidity, such as diabetes. Reliable data on co-morbidity and its influence on medical consumption may improve the cost estimates, especially for elderly people, but at the moment these are not available. If disease-specific data on pharmaceuticals become available for The Netherlands, it is unlikely that the ranking of diseases by costs will change substantially, because drugs only represent $9 \%$ of total health care costs in The Netherlands. Lindgren's ${ }^{7}$ data for Sweden indicate that, except for mental diseases, the ranking of total costs and costs of drugs by disease is quite similar.

The most recent cost estimates for the US date from 1980 , but may still be valid, as comparison of the distribution of US costs by disease for 1980 and 1972 also showed only minor differences. ${ }^{8,36}$ This also holds for the Swedish results regarding 1975 and $1983.7,37$

Although we do not provide a complete analysis of international differences in health care costs, numerous findings point to more aggressive medical practice, higher administration costs and higher prices as the main causes of unparalleled costs in the US. Further research is urgently needed to shed more light on the contribution of epidemiological causes. However, the high costs in the US do not seem to produce better health care and public health for the average American citizen. In the US the amount of care in psychiatric hospitals and nursing homes is substantially smaller than in The Netherlands and

Table 5 Indices for the predicted development of health care costs by disease category, due to demography in The Netherlands, for the years 2010 and $2030(1988=100)$

\begin{tabular}{lcc}
\hline Disease category & \multicolumn{2}{c}{ Year } \\
\hline All diseases & 2010 & 2030 \\
& 121 & 139 \\
Prostate cancer & & \\
Dementia & 141 & 206 \\
Heart failure & 148 & 203 \\
Stroke & 143 & 196 \\
Lung cancer & 140 & 193 \\
Male genital diseases & 142 & 185 \\
Diabetes & 136 & 181 \\
Ischaemic heart diseases & 134 & 174 \\
& 141 & 174 \\
\hline
\end{tabular}


Sweden ${ }^{21}$ (table 3). Life expectancy at birth is lower in the US than in The Netherlands and Sweden, while infant mortality is higher. ${ }^{23}$ This may be closely related to the fact that approximately $14 \%$ of Americans are uninsured. ${ }^{38}$ In The Netherlands the number of uninsured is negligible $(0.3-0.5 \%)$ and Sweden has a national health care system ensuring universal access to health care. Preventive care in the US is underdeveloped, resulting in, for example, low immunization rates for infants. ${ }^{39,40}$

With respect to the impact of demographic change on costs we assumed that the relation between age, sex and health care costs for 1988 is a valid estimate for the future. In the absence of reliable evidence of the influence of epidemiology and technology on future medical consumption this estimate provides a reasonable baseline scenario, to be modified after more detailed research. If, for example, the health care costs for the elderly increase relatively more than for the young, our calculations may underestimate the true costs of ageing. Further research on the development of the relation between age, morbidity and health care costs is needed to improve these estimates.

We thank professor D. Rice and professor B. Lindgren for providing additional details on their studies.

\section{REFERENCES}

1 Schieber C, Poullier JP, Greenwald LM. Health care systems in twenty-four countries. Health Affairs 1991;10(3):22-38.

2 WV (National Department of Health and Welfare). Financial overview of health care 1990 (in Dutch). The Hague: SDU, 1989.

3 Koopmanschap MA, Roijen L van, Bonneux $L$ Cost of illness in The Netherlands (in Dutch). Rotterdam: Department of Public Health and Social Medicine, Erasmus University, 1991.

4 WHO. International classification of diseases, 9th rev, clinical modification (ICD-9-CM). Geneva: WHO, 1975.

5 Casparie AF, Hoogendoorn D. Effects of budgeting on health care services in Dutch hospitals. Am J Public Health 1991;81:1442-7.

6 CBS (Central Bureau for Statistics). National health interview survey 1981-1985. The Hague: CBS, 1988.

7 Lindgren B. The economic impact of illness. In: Abshagen U, Munnich FE, eds. Cost of illness and benefits of drug treatment. Munich: W. Zudkschwerdt Verlag, 1990:12-20.

8 Rice DP, Hodgson TA Kopstein AN. The economic cost of illness: a replication and update. Health Care Fin Rev 1985;7:61-80. 9 CBS (Central Bureau for Statistics). Demographic forecast, medium variant. Monthly statistics on demography, December. Voorburg: CBS, 1989.

10 Berg $P$ van der. Further specification of features of the Europe-scenario (in Dutch). The Hague: Central Planning Bureau, 1991.

11 Huisman R. A simulation model for the care for the elderly [dissertation in Dutch]. Maastricht: University of Limburg, 1990.

12 Hodgson TA, Kopstein AN. Health care expenditures for major diseases in 1980 (induding unpublished appendix). Health Care Fin Rev 1984;4:1-12.

13 Waldo D, Sonnefeld S, McKusick D, Arnett R. Health expenditures by age group, 1977 and 1987 . Health Care Fin Rev 1989;10(4):116-8.

14 Jorm AF, Korten AE, Henderson AS. The prevalence of dementia: a quantitative integration of the literature. Acta Psychiat Scand 1987;76:465-79.
15 Ritchie K, Kildea D, Robine JM. The relationship between age and the prevalence of senile dementia: a meta-analysis of recent data. Int J Epidemiol 1992;21(4):763-9.

16 Yeargin-Allsopp M, Murphy CC, Oakley GP, Siker RK. A multiple-source method for studying the prevalence of developmental disabilities in children: the Metropolitan Atlanta Developmental Disabilities Study. Pediatrics 1992;89:624-30.

17 Dupont A. 140 years of Danish studies on the prevalence of mental retardation. Acta Psychiat Scand 1989;348(8 Suppl):105-12.

18 Banta $D, B o s M$. The relation between quantity and quality with coronary artery bypass grafting. Health Policy 1991;18:1-10.

19 OECD. OECD Health Data. Paris: OECD/CREDES, 1991.

20 SIG (Information Centre for Health Care). Yearbook on hospital registration 1989. Utrecht: SIG, 1990.

21 United Nations. Statistics of road traffic accidents in Europe. New York: UN, 1987.

22 Beeck E van, Mackenbach JP, Oortmarssen GJ van,

Barendregt JJM, Habbema JDF, Maas PJ van der. Scenarios for the future development of accident mortality in The Netherlands. Health Policy 1989;11:1-17.

23 WHO. World health statistics annual 1989, 1990. Geneva: WHO, 1990, 1991.

24 US Bureau of the Census. Current population reports, series P-25. Washington: Government Printing Office, 1989.

25 Woolhandler S, Himmelstein DU. The deteriorating administrative efficiency of the US health care system. $N$ Engl J Med 1991;324:1253-8.

26 Greenspan AM, Kay HR, Berger BC, Greenberg RM, Greenspon AJ, Spuhler Gaughan MJ. Incidence of unwarranted implantation of permanent cardiac pacemakers in a large medical population. N Engl J Med 1988;318:158-63.

27 Kahn KL, Kosecoff J, Chassin MR, et al. The use and misuse of upper gastro-intestinal endoscopy. Ann Int Med 1988;109:664-70.

28 Winslow CM, Kosecoff JB, Chassin M, Kanouse DE, Brook RH. The appropriateness of performing coronary artery bypass surgery. JAMA 1988;260:505-9.

29 Center for Health Policy Research. The costs of medical professional liability in the 1980s. Chicago: American Medical Association, 1990.

30 Robinson JC, Luft HS. The impact of hospital market structure on patient volume, average length of stay, and the cost of care. J Hith Econ 1985;4:333-56.

31 OECD. Financing and delivering health care: a comparative analysis of OECD countries. Paris: OECD, 1987.

32 Rice DP. Demographic realities and projections of an aging population. In: Andreopoulos S, Hogness JR, eds. Health care for an aging society. New York: Churchill Livingstone, 1989:43-61.

33 Baumol WJ. Macroeconomic of unbalanced growth: the anatomy of urban crisis. Am Econ Rev 1967;57:415-26.

34 CPB. Development of productivity in the health care sector: defining concepts and quantification for the period 1981-1985.

The Hague: CPB, 1987.

35 Stehbens WE. An appraisal of the epidemic rise of coronary heart disease and its decline. The Lancet 1987;1:606-11.

36 Cooper BS, Rice DP. The economic cost of illness revisited. Soc Secur Bull 1976;39:21-36.

37 Lindgren B. Cost of illness in Sweden 1964-1975. Lund: Lund Economic Studies, 1981.

38 Congressional Budget Office. Rising health care costs: causes, implications and strategies. Washington DC: Government Printing Office, 1991.

39 Starfield B. Primary care and health: a cross-national comparison. JAMA 1991;266:2268-71.

40 Children's Defence Fund. Who is watching our children's health: immunization status of American children. Washington DC: Children's Defence Fund, 1987.

41 National Hospital Institute. Financial statistics on hospitals. Utrecht: National Hospital Institute, 1988.

42 National Hospital Institute. Financial statistics on hospitals. Utrecht, 1988.

Received 22 July 1993, accepted 18 November 1993 